\title{
Effect of postharvest practices including degreening on citrus carpoplane microbial biomes
}

\author{
A Gomba, L Chidamba and L Korsten* \\ Department of Plant and Soil Sciences, University of Pretoria, Private Bag X20, Hatfield, 0028, South Africa. \\ * Corresponding author. Mailing address: Department of Plant and Soil Sciences, University of Pretoria, \\ South Africa. Phone: +2712420 3295. Fax: +2712420 4588. Electronic mail address: lise.korsten@up.ac.za.
}

\section{Abstract}

Aims: To investigate the effect of commercial citrus packhouse processing steps on fthe ruit surface microbiome of Clementines and Palmer navel oranges.

Methods and Results: Viable bacteria, yeasts and fungi counts, and pyrosequencing analysis of the 16S rRNA and ITS were used to evaluate the community structure and population dynamics of phylloepiphytic bacteria and fungi associated with commercial postharvest processing. Drenching significantly reduced microbial counts in all cases except for yeasts on navels, while the extend of degreening effects varied between the citrus varieties. Pyrosequencing analysis showed a total of 4409 bacteria and 5792 fungi non-chimeric unique sequences with an average of 1102 bacteria and 1448 fungi reads per sample. Dominant phyla on the citrus carpoplane were Proteobacteria (53.5\%), Actinobacteria (19.9\%), Bacteroidetes (5.6\%) and Deinococcus-Thermus (5.4\%) for bacteria and Ascomycota (80.5\%) and Basidiomycota (9.8\%) for fungi. Beginning with freshly harvested fruit fungal diversity declined significantly after drenching, but had little effect on bacteria and populations recovered during degreening treatments, including those for Penicillium spp.

Conclusion: Packhouse processing greatly influences microbial communities on the citrus carpoplane.

Significance and Impact of the Study: A broad orange biome was described with pyrosequencing and gave insight into the likely survival and persistence of pathogens important in the reduction of postharvest losses.

Keywords: citrus biome, drenching, degreening, bacteria, fungi yeast, pyrosequencing 


\section{Introduction}

The carpoplane (fruit surface) is colonised by a variety of microorganisms that include several species of bacteria, fungi and yeasts (Abdelfattah et al. 2015; Jensen et al. 2013). Some plant associated microbes are beneficial to the growth and development of the host while others have a negative effect on disease development and overall quality (Andrews and Harris 2000). In agriculture, microbes of food safety concern introduced from various sources including contaminated soil, irrigation water, animals and manure can also form part of the carpoplane community (Beuchat and Ryu 1997). Several factors such as geographical region, plant age and farming practices can influence the establishment of microorganisms on the carpoplane (De Jager et al. 2001; Williams et al. 2013; Perazzolli et al. 2014; Pinto et al. 2014; Taylor et al. 2014).

Early seasonal citrus varieties reach physiological maturity and are ready for the market while the peel is still green (Smilanick et al. 2006). Peel colour is an important criteria determining marketability as consumers associate the green colour with immature fruit (Eckert and Brown 1986). To meet consumers' expectations of the "perfect orange", oranges, degreening is used as a postharvest treatment to hasten the natural colour break of early seasonal fruit (Smilanick et al. 2006). Degreening is achieved by exogenous applications of ethylene gas to freshly harvested fruit at 5 to $10 \mu \mathrm{l}^{-\mathrm{L}} ; 90$ to $95 \%$ relative humidity for 1 to 5 days (Ritenour et al. 2003) with temperatures varying according to region.

Notwithstanding its advantages in improving fruit visual appearances, studies have shown that ethylene degreening can result in increased postharvest fruit decay of citrus fruit (Smilanick et al. 2006). It has been reported that exogenous ethylene applications increase susceptibility of citrus to decay and can directly stimulate the growth of certain pathogens (Brown 1992). Further, exposure of citrus fruit to degreening is highly conducive to the development of decay (Morris and Lieberman 1988). In California and other arid growing regions, degreening at $20{ }^{\circ} \mathrm{C}$ to $22{ }^{\circ} \mathrm{C}$ is conducive to the development of green mould caused by Penicillium digitatum (Pers.:Fr) Sacc. (Smilanick et al. 2006). Conversely, degreening temperatures of 28 to $29{ }^{\circ} \mathrm{C}$ used in Florida including other subtropical areas partially inhibit the growth of $P$. digitatum but stimulate the development of stem-end rot caused by 
Lasiodiplodia theobromae (Pat.) Griffon and Maubl (Brown 1986) and anthracnose caused by Colletotrichum gloesporioides Penz (Eckert and Eaks 1989). Degreening is bound to exert selective pressure to microbial communities on the citrus carpoplane due to sudden changes of environmental conditions and the direct impact of ethylene on the microorganisms.

Fungicide drenching is a common postharvest practice applied to freshly harvested fruit just before degreening to reduce microbial populations and -the incidence of decay (Ritenour et al. 2003; Smilanick et al. 2006). It is also common practice to hold citrus fruit for a few days outside the packing house during peak harvesting and packing periods. However, fruit that is delayed during the packing process for more than $24 \mathrm{hrs}$ must be drenched to minimise decay (Brown and Miller 1999). There is no information regarding the impact of drenching and delay on packing and the microbial community structure of the citrus carpoplane.

Recently, the use of culture-independent techniques in microbial ecology has improved our knowledge on the microbial communities inhabiting surfaces on agricultural crops. Unlike classical microbiological approaches, culture-independent techniques capture a large proportion of microbes revealing a more complex dynamic community than that attained with traditional methods (Abdelfattah et al. 2015; Lopez-Velasco et al. 2011; Pinto et al. 2014). Among the many culture-independent techniques, pyrosequencing is a recently developed next-generation sequencing technology that has been used to characterise microbial communities in numerous environments including the rhizosphere (Inceoglu et al., 2011; Peiffer et al. 2013), phyllosphere and carposphere (Bodenhausen et al. 2013; Taylor et al. 2014; Abdelfattah et al. 2015) and recently roof-harvested rain water (Chidamba and Korsten 2015). We are not aware of such studies conducted to date to describe the impact of commercial postharvest treatments including fungicide drenching and degreening on the community structure of the citrus carpoplane. A close examination of the microbial diversity of the citrus carpoplane as affected by packhouse procedures can improve our understanding of the behaviour of these communities, especially as they may affect the quality and safety of the packed product.

This study was carried out to investigate changes in fungal and bacterial community profiles on citrus fruit subjected to commercial postharvest practices including degreening treatments 
using traditional plate count methods and pyrosequencing. Plate counts were performed to quantify changes in culturable microbial populations following each packhouse operational step.

\section{Materials and methods}

\section{Fruit sampling and treatments}

The present study was conducted using partially coloured, physiologically mature Clementines and Palmer navels freshly harvested from commercial orchards at a farm in the Eastern Cape Province, South Africa. Fruit samples were collected from the same batch moving through commercial postharvest practices including harvesting bins prior to fungicide drenching (freshly commercially harvested), drenched fruit prior to degreening (drenched) and degreened fruit before chlorine treatment (degreened with ethylene). Drenched fruit subjected to degreening conditions without ethylene treatment was included as the control (non-ethylene degreened). Untreated fruit held at ambient indoor conditions at the packhouse for the duration of the degreening period (three days) was included for comparative purposes. Samples were collected aseptically in five replications of 10 fruit at each sampling point, clearly labelled, sealed, placed in separate sterile cooler boxes with ice packs and transported by air under refrigeration conditions to the Plant Pathology Laboratories, University of Pretoria. A schematic fruit sampling protocol is shown in Figure 1.

The fungicide drench consisted of thiabendazole, 1000 ppm; pyremithanil, $1000 \mathrm{ppm}$; guazatine, 500 ppm and 2.4-dichlorophenoxyacetic acid. Degreening was accomplished by exposing fruit to continuous ethylene flow in regulated degreening rooms $\left(3 \mu 1^{-\mathrm{L}}\right.$ ethylene, 21-23 ${ }^{\circ} \mathrm{C}$ and $\left.94 \% \mathrm{RH}\right)$ for three days. Freshly harvested and drenched samples were transported to the laboratory for analysis soon after collection while the rest were transported after their respective treatments. Sample processing and microbial analysis commenced immediately upon receipt. 


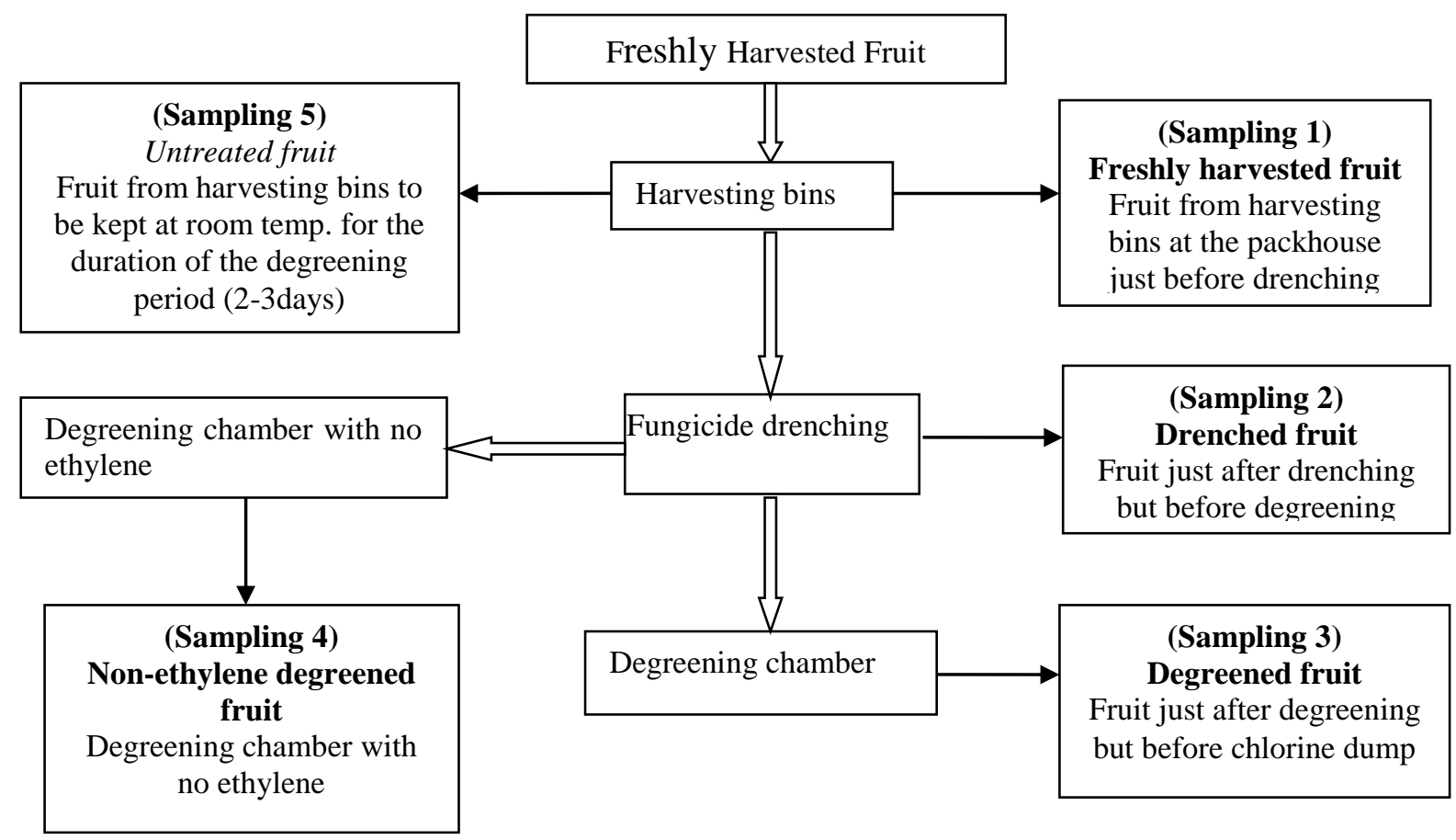

Figure 1. Fruit sampling protocol showing the points where fruit samples were collected during commercial degreening

\section{Sample processing and microbiological analyses}

Sample processing and microbiological analyses were conducted following standard microbiological procedures briefly; fruit samples were aseptically transferred into a $2 \mathrm{~L}$ sterile glass beaker containing $1 \mathrm{~L}$ sterile $0.1 \%(\mathrm{w} / \mathrm{v})$ buffered peptone water (BPW) supplemented with 0.02\% (v/v) Tween 80 (Associated Chemical Enterprises, Johannesburg). Microbial epiphytes on fruit surfaces were dislodged by sonication in a digital heated ultrasonic cleaner (Eumax, UD200SH-6L, Labotec, Johannesburg) for $5 \mathrm{~min}$ at 200W and $50 \mathrm{~Hz}$. Microbiota washings were concentrated by vacuum filtration onto $0.45 \mu \mathrm{m}$ nitro-cellulose filters (Sartorius Stedim Biotech, Goettingen, Germany).

Following filtration, the membranes were aseptically transferred into $9 \mathrm{ml}$ tryptone soy broth (TSB) and thoroughly vortexed to dislodge the microbes. Ten-fold serial dilutions were then conducted in $0.1 \%$ BPW followed by spread plating $0.1 \mathrm{ml}$ aliquots in duplicate onto Standard 1 nutrient agar supplemented with $0.1 \%$ cycloheximide (w/v) (Sigma Aldrich, Johannesburg) and malt extract agar supplemented with $0.025 \%$ chloramphenicol (w/v) (Centaur Labs) for enumeration of bacteria, and fungi and yeasts, respectively. Plates were 
incubated for 3-7 days at $25{ }^{\circ} \mathrm{C}$ after which, total viable counts were enumerated and reported as $(\mathrm{CFU})^{-\mathrm{cm} 2}$ (De Roever 1998). All microbiological media was purchased from Merck (Johannesburg) unless otherwise stated.

\section{Sample selection DNA extraction and pyrosequencing analysis}

Samples of palmer navels were randomly selected from freshly harvested, drenched, degreened and untreated oranges to elucidated effects of postharvest processing on biomes (Figure 1). Following serial dilutions (described above), a pellet of epiphytic microbes was obtained by centrifugation of the remaining microbiota wash at $14000 \times \mathrm{g}$ for 45 to 60 minutes at $4{ }^{\circ} \mathrm{C}$. DNA extraction was performed using the Zymo Research Fungal/Bacterial DNA extraction kit (Zymo Research Co., Orange, CA) according to manufacturer's instructions.

DNA samples were sent to Inqaba Labs (Pretoria, South Africa) for tag encoded pyrosequencing of fungi and bacteria using Roche GS FLX+ 454 pyrosequencer (GATC Biotech, Konstanz, Germany). Amplification of the fungal internal transcribed spacer (ITS) region was performed using primer set ITS1F (CTTGGTCATTTAGAGGAAGTAA) and ITS4R (TCCTCCGCTTATTGATATGC) (McHugh et al. 2014). The 16S rRNA gene for bacteria was amplified using universal bacterial primer set $27 \mathrm{~F}$ (5'AGAGTTTGATCMTGGCTCAG-3') (Weisburg et al. 1991) and 518R (5'ATTACCGCGGCTGCTGG-3') (Muyzer et al. 1993).

\section{Pyrosequencing data processing}

The RDP pipeline (https://pyro.cme.msu.edu/) was used for analysis as previously described (Cole et al. 2013). Sequences of low quality or shorter than $150 \mathrm{bp}$ in length were removed from the pyrosequencing-derived data sets using the RDP pyrosequencing pipeline initial processing (Cole et al. 2013). Chimera were filtered using Uchime 6.0 (Edgar et al. 2011), and aligned with Mothur (Nawrocki et al. 2009). Taxonomic reference database: bacterial 16s and Unite Fungal ITS trainset 07-04-2014: Classifications were carried out at a minimum confidence threshold of $80 \%$; Operational taxonomic units (OTUs) for rarefaction analysis were clustered at $0 \%, 3 \%, 5 \%$ and $10 \%$ distance cut off. Diversity indices, Shannon and 
Chao1 were also calculated on the RDP platform. Hierarchical clustering was performed for bacteria diversity variation with Bray-Curtis distance using average linkage.

\section{Statistical analysis}

A two way analysis of variance (ANOVA) for viable counts of culturable bacteria, fungi, and yeasts was conducted using the Genstat ${ }^{\circledR}$ 7.22 Discovery Edition software (VSN, 2009), and the means were compared using the least significance difference at 0.05 level of significance.

\section{Results}

\section{Culturable microbial population changes}

Figure 2 shows microbial population changes on Clementines and Palmer navels at particular stages during packhouse processing. Significant varietal differences in bacterial counts were observed between the two citrus varieties at every packing stage except on untreated fruit that was stored at ambient indoor conditions for three days. Similar trends were observed for fungal and yeast counts with significant differences observed for fungal counts at every step while there were no significant varietal differences for yeast counts under non-ethylene degreening conditions only. It is worth noting that Palmer navels had significantly higher fungal and yeast counts on freshly harvested and untreated fruit held at ambient indoor conditions for three days.

Initial bacterial counts on freshly harvested Clementines were $4.2 \operatorname{logs} \mathrm{CFU}^{-\mathrm{cm} 2}$ and were significantly reduced to $2.6 \log \mathrm{CFU}^{-\mathrm{cm} 2}$ by the fungicide drench. Degreening with ethylene resulted in a significant increase $(0.2 \mathrm{log}$ units $)$ in bacterial populations on drenched Clementines while these populations were not significantly affected under non-ethylene degreening conditions. Freshly harvested Clementines had fungal and yeast counts of approximately $2 \log$ units. Fungal counts were significantly reduced ( $0.5 \log$ units) by the fungicide drench and remained relatively unchanged under ethylene degreening but increased (0.5 log units) significantly under non-ethylene degreening conditions. Yeast counts increased significantly ( $0.5 \mathrm{log}$ units) following the fungicide drench but were significantly reduced under both degreening conditions with a greater change observed in the presence of 


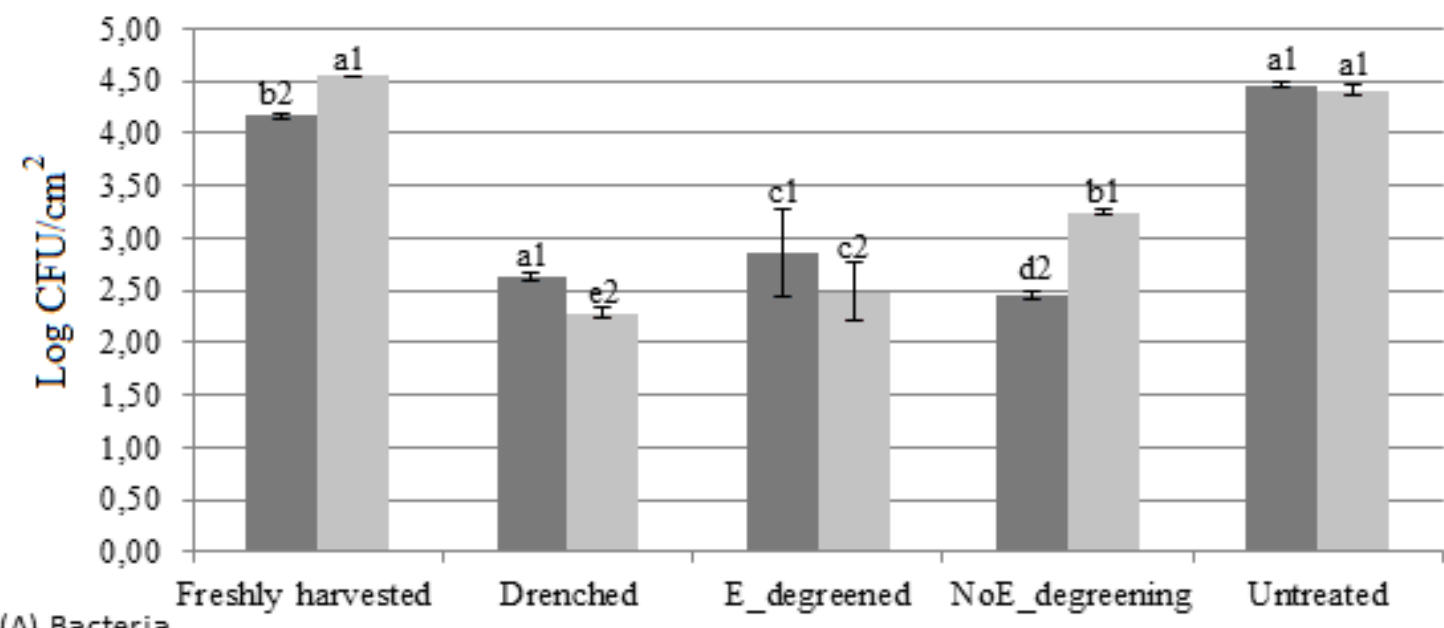

(A) Bacteria

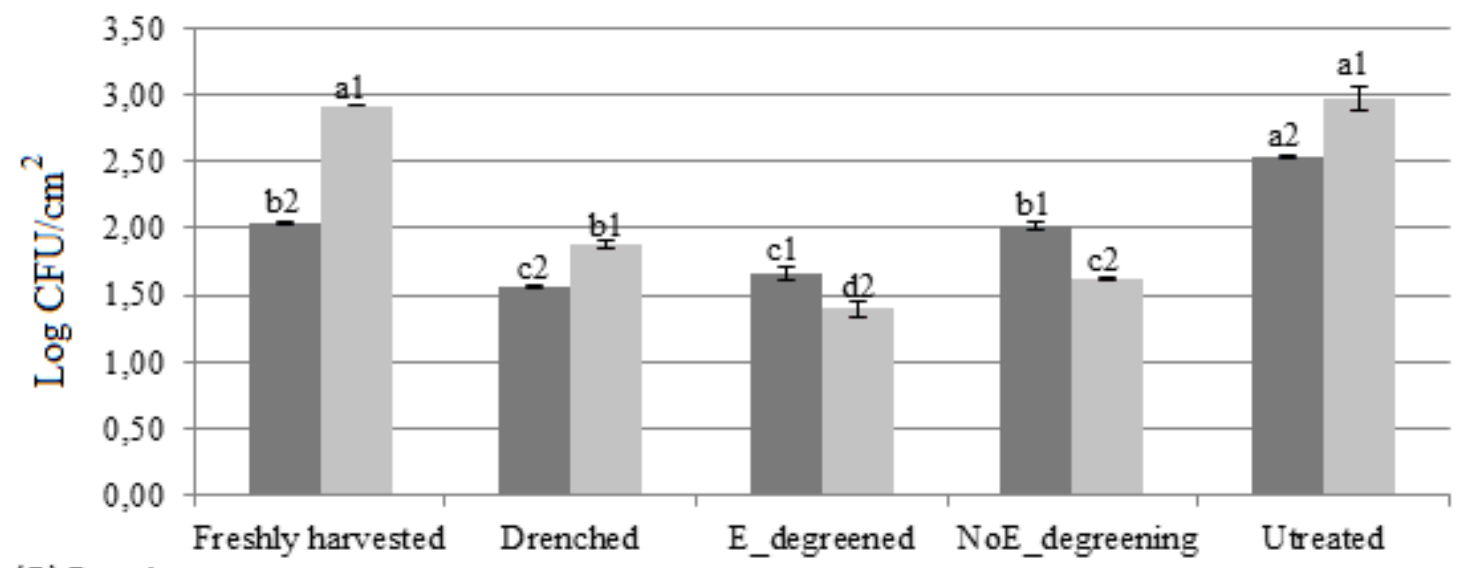

(B) Fungi

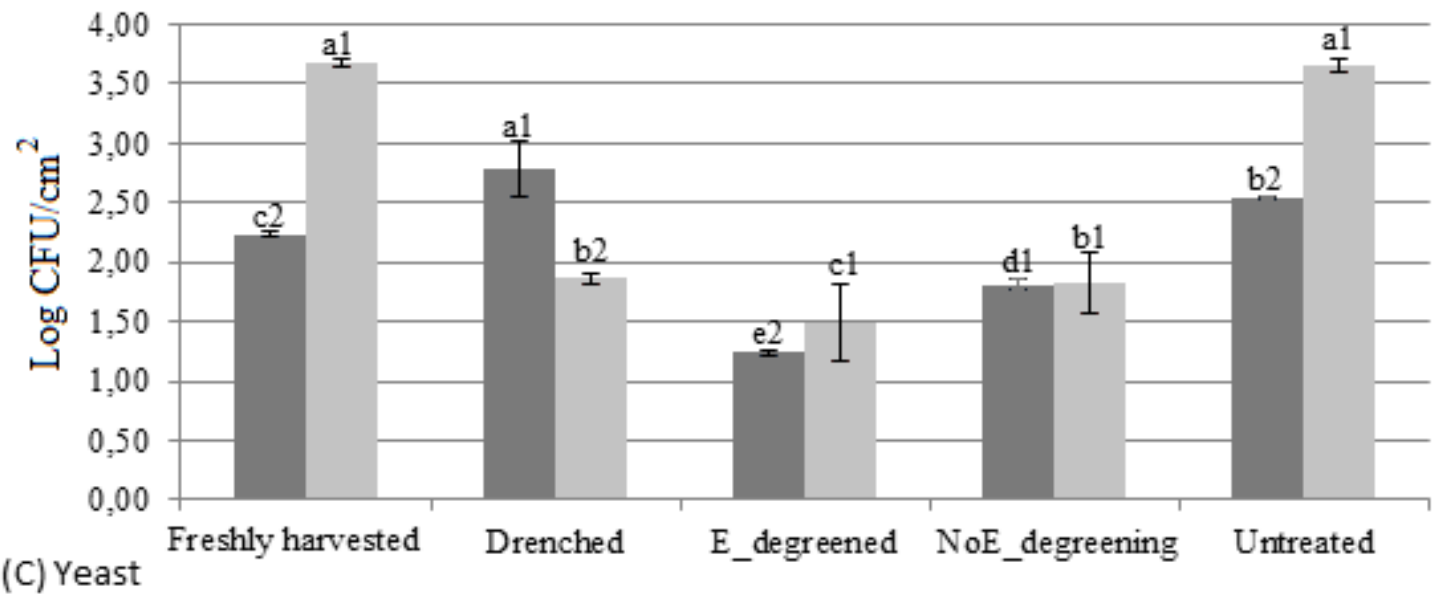

Processing stages

\section{Key: $₫$ Clementine $\quad$ Palmer navel}

Figure 2. Microbial population changes of Clementines and Palmer navels during selected packhouse operations. Within the same variety, means sharing the same letter are not significantly different $(p>0.05)$; Within the same packhouse step, means sharing the same number are not statistically different $(p>0.05)$. E_degreened is degreened with ethylene; NoE_degreened is degreened with no ethylene. Each bar is the mean of five replications (ten fruit per replication). Standard deviations are shown in error bars 
ethylene. Storing freshly harvested Clementines under ambient room conditions for the duration of the degreening period (three days) resulted in a slight but non-significant increase in bacterial counts whereas fungal and yeast counts increased significantly under the same conditions.

With regards to Palmer navels, initial microbial populations were $4.5 \log \mathrm{CFU}^{-\mathrm{cm} 2}$ (bacteria), $2.9 \log \mathrm{CFU}^{-\mathrm{cm} 2}$ (fungi) and $3.7 \log \mathrm{CFU}^{-\mathrm{cm} 2}$ (yeast) and were significantly reduced following the fungicide drench. Bacterial counts increased significantly under ethylene (0.2 log units) and non-ethylene (0.8 log units) degreening conditions whereas the opposite was true for fungal counts under the same conditions. Yeast counts on Palmer navels also declined (1.8 $\log$ units) significantly during ethylene degreening but did not change under non-ethylene degreening conditions. Holding harvested Palmer navels at ambient temperature for three days did not result in significant changes on total microbial counts.

\section{Pyrosequencing of microbial communities}

\section{Sequencing depth}

Pyrosequencing of representative samples from the four packhouse processing resulted in 5 069 bacteria and 6338 fungi sequence reads that passed quality control algorithm of the Roche 454 platform. The RDP pipeline initial processing including trimming and quality filtering of sequences that were at least $150 \mathrm{bp}$ long resulted in 4431 bacteria and 5855 fungi reads. Sequences were filtered for chimera and a total of 4409 bacteria and 5792 fungi nonchimeric sequences were used for classification, alignment, clustering and further downstream processing. On average, an individual sample harboured 1102 bacteria and 1 448 fungi reads.

The unique sequences were clustered at $95 \%$ similarity into OTUs (Keijser et al. 2008). The highest number of OTUs was observed in fungi sequences from degreened orange samples and the least in drenched samples. Freshly harvested (414 OTUs) and untreated (499) samples had similar number of OTUs. All samples had similar OTU abundances (359-465 OTUs) for bacteria sequences, with the highest number of OTUs observed in degreened samples. 


\section{Alpha diversity}

To determine richness and diversity, quality sequences with a read length of at least 150bp per sample were used. The identification of OTUs was done at 5\% (genus level) and 20\% (phylum level) (Pankhurst et al. 2012; Dowd et al. 2008). Saturation of rarefication curves were observed at $10 \%$ sequence divergence, for all samples (Figure 3). Although the phylum level taxonomic diversity can be said to be well represented, the observed rarefaction curves of OTUs at genus (0.05 distance) and species level (0.03 distance) did not plateau. A higher number of reads from samples in this may have provided more comprehensive OTU abundance data of the taxa. However, with our level of sequencing depth, we were able to capture the main components of the samples community diversity at the species and genus level as the rarefaction plots had begun to plateau towards the end of the curves.
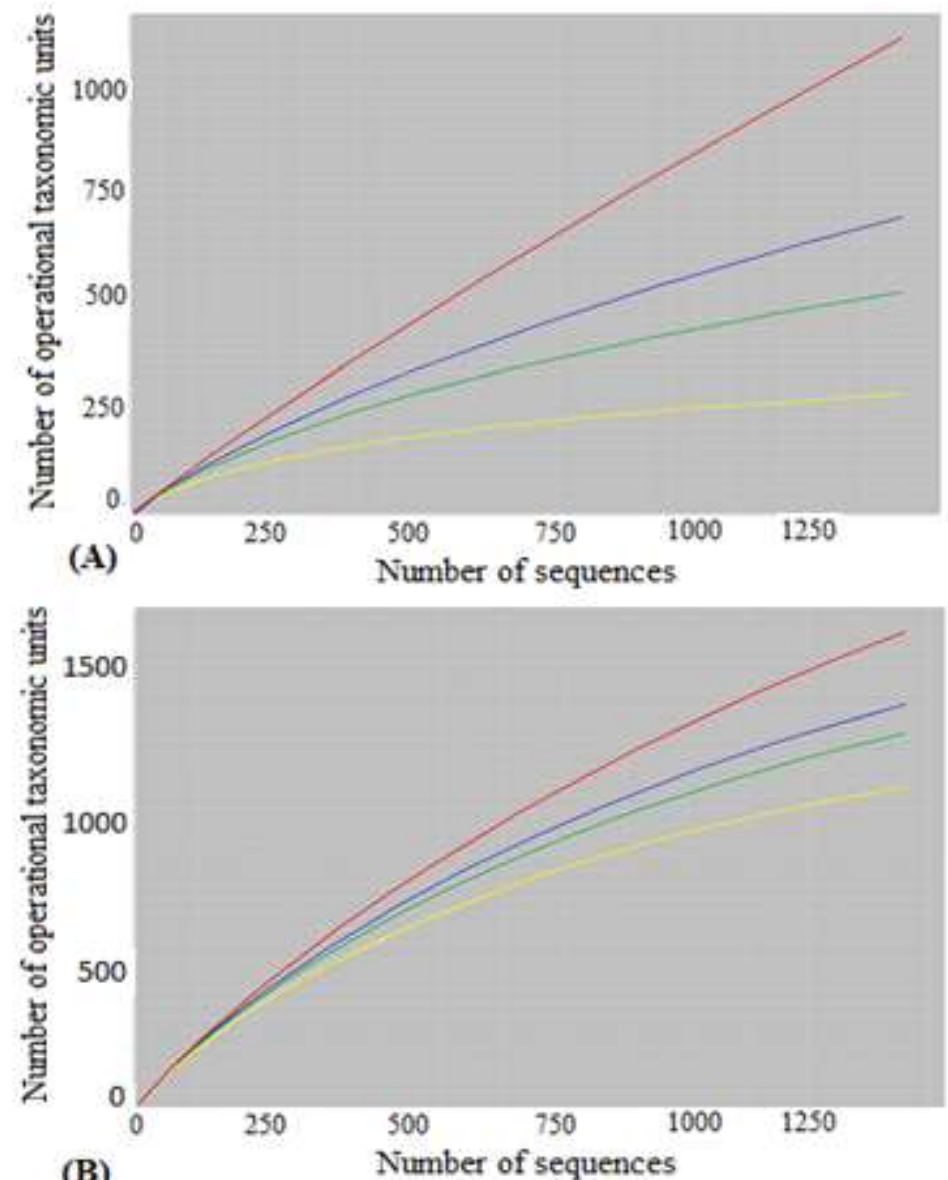

(B)

0.00 distance -0.03 distance -0.05 distance -0.10 distance

Figure 3. Rarefication curves for bacteria (A) and fungi (B) species richness and diversity for untreated oranges as a representative of the observed trends in other samples (including for freshly harvested, drenched and degreened oranges). 
Freshly harvested and untreated oranges had the highest microbial diversity (OTUS, Shannon and Chao1 indices), while the least diversity was observed in drenched oranges. An interesting gradient is observed with regard to the processing stages. Microbial diversity was high for both freshly harvested and untreated samples. However, it declined with drenching and recovered with degreening. The Chao1, species richness estimator and Shannon diversity indices indicated that in general, the most diverse populations were found in degreened and unprocessed orange samples and the least in drenched orange samples (Table 1).

Table 1. Alpha diversity parameters of bacterial and fungal communities from freshly harvested, drenched, degreened and untreated oranges

\begin{tabular}{|c|c|c|c|c|c|}
\hline \multirow{2}{*}{$\begin{array}{c}\text { Sequence } \\
\text { Type }\end{array}$} & \multirow{2}{*}{ Sample Source } & \multicolumn{4}{|c|}{ Diversity indices } \\
\hline & & $\mathbf{N}^{\mathrm{a}}$ & OTU $^{b}$ & Chao & Shannon \\
\hline \multirow{4}{*}{ 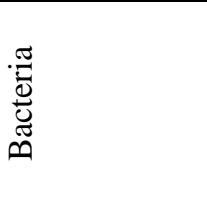 } & Freshly harvested & 1002 & 350 & 613.50 & 5.26 \\
\hline & Drenched & 1068 & 398 & 696.77 & 5.49 \\
\hline & Degreened & 1361 & 465 & 838.51 & 5.55 \\
\hline & Untreated & 978 & 359 & 666.59 & 5.35 \\
\hline \multirow{4}{*}{$\begin{array}{l}\sqrt[50]{50} \\
\Xi\end{array}$} & Freshly harvested & 830 & 414 & 607.38 & 5.72 \\
\hline & Drenched & 86 & 71 & 591.00 & 4.11 \\
\hline & Degreened & 3150 & 1265 & $1,728.37$ & 6.64 \\
\hline & Untreated & 1181 & 499 & $1,069.51$ & 5.52 \\
\hline
\end{tabular}

${ }^{\mathrm{a}}$ Total number of sequences

${ }^{\mathrm{b}}$ Operational taxonomic unit.

The Chao1 richness varied between 613.5 and 838.51 for bacteria and 591 and 1728.4 for fungi. The Shannon index varied between 5.48 and 5.55 for bacteria and 4.1 and 6.64 for fungi. In all cases, degreened samples had the highest level of diversity followed by unprocessed and the least was observed in drenched samples. Generally, there was limited diversity level with respect to bacteria, while a wide variation in fungal populations was observed between the orange processing stages.

\section{Unique and shared bacterial taxa}

At phylum level $87.9 \%$ of sequences were classified into ten phyla of the domain bacteria Proteobacteria dominated the data set (53.5\% of all reads), while $12.1 \%$ of the reads could not be classified to any of the known phyla at a probability of 0.8 or higher (unclassified bacteria), $19.9 \%$ of reads were classified as Actinobacteria, $5.6 \%$ as Bacteroidetes, and $5.4 \%$ 
as Deinococcus-Thermus. Cyanobacteria were only detected in degreened $(0.4 \%)$ and untreated $(1.1 \%)$ samples. Other unique distributions were observed in phylum TM7 and Verucomicrobia found only in degreened samples, Armatimondetes in degreened and untreated, Firmicutes and Planctomycetes in all samples except unwashed.

\section{Genus diversity}

To evaluate the prevalence of various OTUs, samples were compared for their variations at genus level. In total, 64 genera were detected from the total amplicon sequence library (Figure 4). A number of genera were found on all samples however genera with high relative prevalences in unique samples included Belnapia in degreened and drenched samples, Methylobacterium in drenched and untreated, Deinococcus and Kocuria in untreated samples. The genera Armatimonas, Massilia, Pseudomonas and Williamsia were unique to drenched and freshly harvested samples; Arthrobacter, Kineococcus and Spirosoma to degreened and drenched samples; Paracoccus and Rhodococcus to degreened and freshly harvested; Microvirga to freshly harvested and untreated and Patulibacter to degreened and untreated oranges.

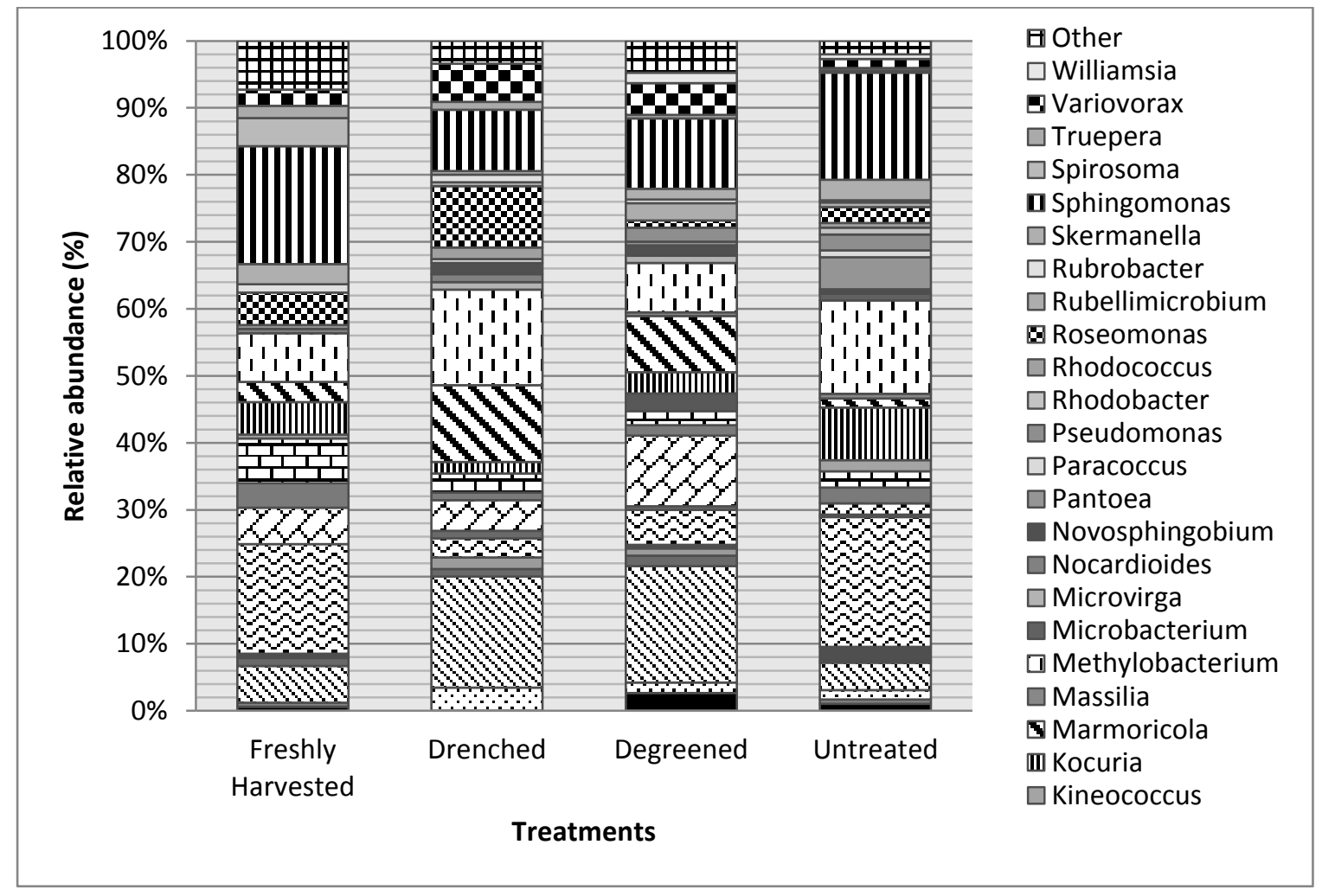

Figure 4. Average relative abundance $(\%)$ of the reads classified into the predominant bacterial genera by individual samples. 
Unique genera with respect to the different samples included Isosphaera, Altererythrobacter, Enterococcus, Humicoccus, Mycobacterium, Nannocystis, Stenotrophomonas, Thermomonas, Vasilyevaea in degreened samples; Adhaeribacter, Aeromicrobium, Aquabacterium, Brachybacterium, Bradyrhizobium, Nocardiopsis, Pedobacter, Planococcus, Pseudoclavibacter, Rhodocytophaga in unwashed samples; Acinetobacter, Agrococcus, Angustibacter, Larkinella, Microbacterium and Rhodobacter in untreated samples and Craurococcus, Filimonas, Modestobacter and Mucilaginibacter in drenched samples. Genera not detected in specific samples included Actinomycetospora, Curtobacterium and Pantoea in drenched samples; Aurantimonas, Brevundimonas, Delftia, Novosphingobium and Rubellimicrobium in unwashed samples; Blastococcus in untreated samples and Nocardioides in degreened samples.

\section{Fungal diversity}

Fungal phyla represented in the 5247 ITS gene sequences included: Ascomycota, Basidiomycota and Chytridimycota. Dominant fungal genera ( $>1 \%$ of total populations) that could be identified in samples included Davidiella, Epicoccum, Cryptococcus_1, Aplosporella, Penicillium, Sporobolomyces, Coprinellus, Cryptococcus, Zymoseptora and Acremonium (Figure 5). Considering the samples from the different stages, the genera Acremonium and Coprinellus were not detected in unwashed samples and Zymoseptoria in degreened samples. The genera Davidiella was the most dominant in all samples. Other dominant genera with respect to unique processing stages included Aplosporella and Sporobolomyces in degreened oranges and Cryptococcus_1 in unwashed samples.

Genera detected in relatively low abundances ( $<3 \%$ per sample) but with unique distributions included Neophaeosphaeria detected only in degreened oranges; Coniothyrium and Preussia in drenched oranges, Diatrypaceae_unidentified and Dioszegia in freshly harvested oranges and the genera Ascochyta, Chrysosporium, Gibberella, Hypocreales_unidentified_1, Peniophora, Pichia, Pleosporales_unidentified_1, Sordariomycetes_unidentified_1, Stephanonectria, Torula and Uwebraunia in untreated samples. The genera Leptosphaerulina, Ascomycota_unidentified_1_1, Phoma and Ramularia were detected in all processing stages except from degreened samples. The genera detected only in freshly harvested and untreated samples included Alternaria, Tremellomycetes_unidentified_l and 
Periconia while the genus Agaricales_unidentified_1 was detected only in drenched and untreated samples.

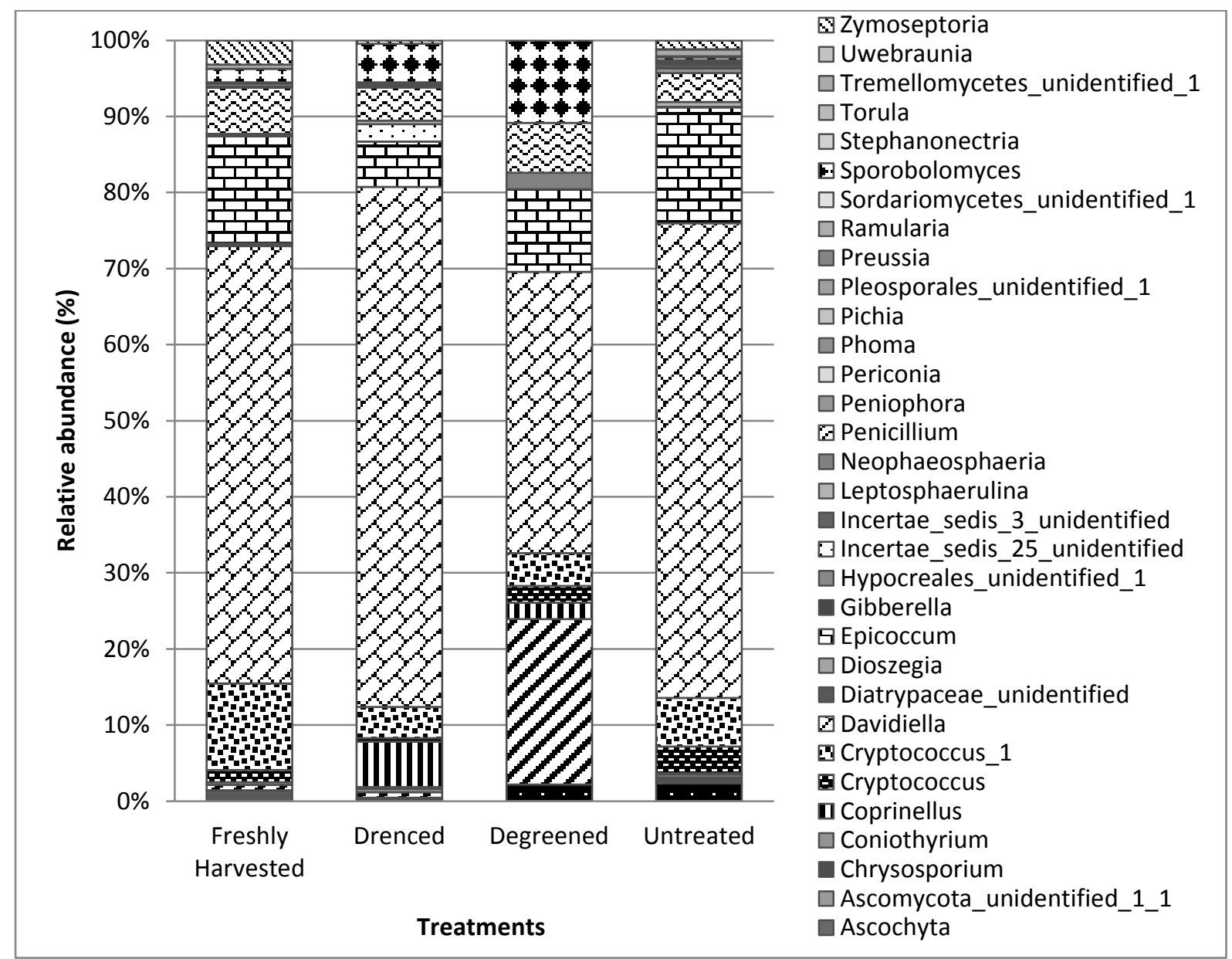

Figure 5. Average relative abundance $(\%)$ of the reads classified into the predominant fungal genera by individual samples.

\section{Bray-Curtis distance analysis}

Freshly harvested, drenched, degreened and untreated oranges were tested for community level diversity with Bray-Curtis distance with average linkage. Bray-Curtis distance measures between groups dissimilarity/similarity based on OTU abundances and the result is influenced by the most abundant species. The analysis results were visualized through a tree cluster diagram. Differences between samples showed marked clustering differences between the samples (Figure 6). Drenched samples were clustered away from the other three samples. Freshly harvested, degreened and untreated were clustered together although degreened and untreated samples had more similar community abundances. 


\section{Hierachical clustering}

Distance: 0.03; Distance Function: Bray-Curtis distance (average linkage)

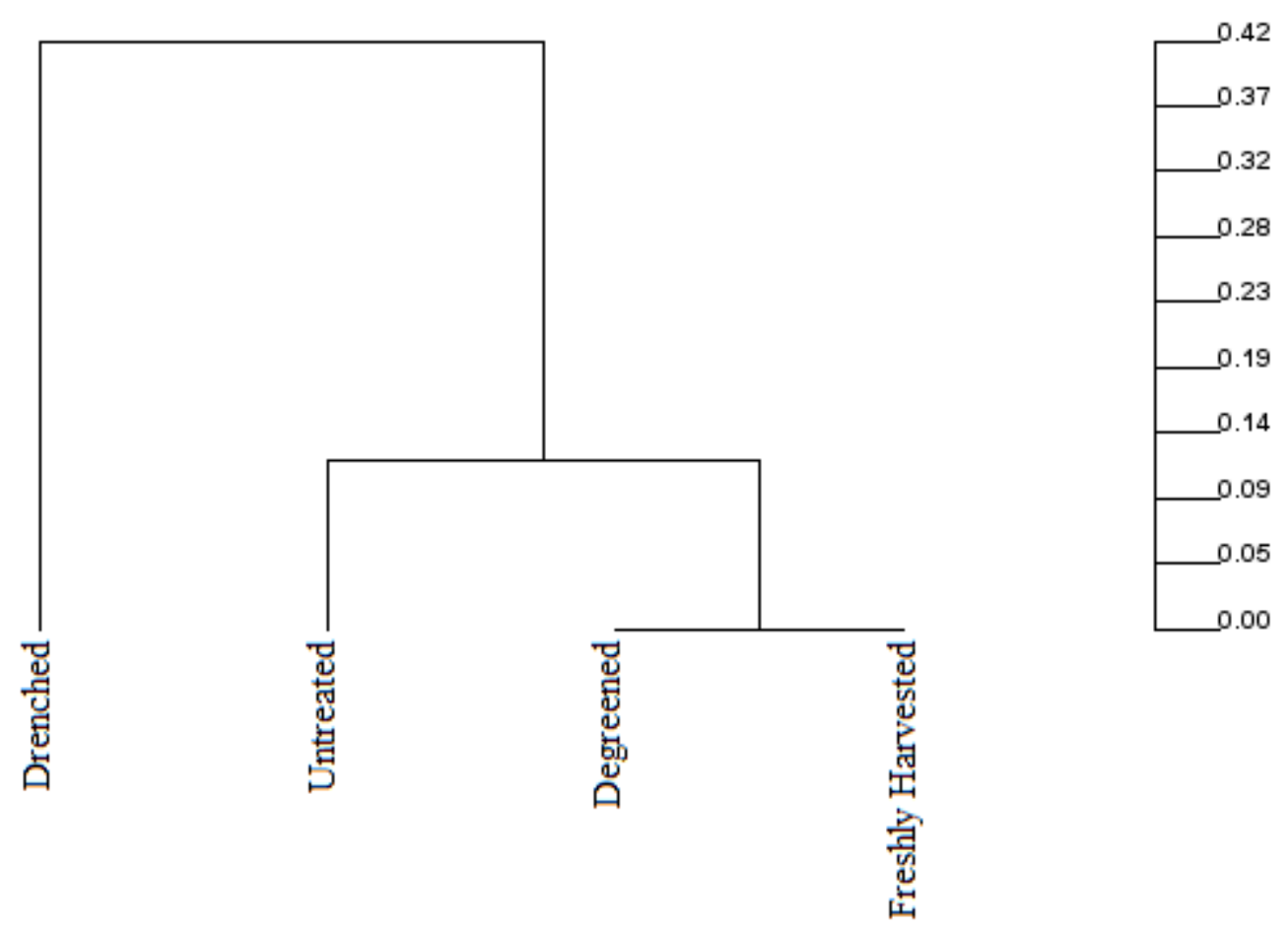

Figure 6. Hierarchical clustering for bacteria with Bray-Curtis distance using average linkage.

\section{Discussion}

\section{Culturable microbial population changes during packhouse processing}

Comparisons drawn between the two citrus varieties and the packing procedures revealed that the rate of microbial (bacterial, fungal and yeast) survival, proliferation or reduction on fruit surfaces depended on the citrus variety and the processing stage evaluated. Although there was no apparent trend on varietal differences at each packing procedure, Palmer navels consistently recorded significantly higher initial microbial counts as well as higher fungal and yeast counts on untreated samples compared to Clementines. Varietal differences are bound to occur and can be attributed to the individual physical and intrinsic characteristics typical of each variety (Keller et al. 2004). Palmer navels are characterised by a rough and uneven skin that may offer a more favourable niche for attachment and proliferation of microbial epiphytes than Clementines that have a much smoother skin. Previous studies have also observed varietal differences in yeast populations on grape berries (Zahavi et al. 2002) and in fungi and yeast biota in fresh berries, grapes and citrus fruits (Tournas and Katsoudas 2005). Although fruit internal quality was not determined in this study, Palmer navels are more 
acidic than Clementines and therefore are expected to harbour more fungi and yeasts and less bacteria compared to Clementines (Keller et al. 2004).

Our results support the concept that drenching fruit prior to degreening reduces microbial loads on fruit surfaces (Smilanick et al. 2006) with the exception of yeast counts that increased significantly on Clementines following the fungicide drench. Using culturedependent techniques, Tournas and Katsoudas (2005) reported that citrus fruit (surface disinfected in dilute (1:10 in sterile distilled water) commercial bleach) including tangerines (24\% of samples) and navel oranges (9\%) supported yeast growth after two weeks of storage at room temperature. The authors speculated that the tiny pits of the uneven citrus skin offered protection to yeast cells hence they were not easily rinsed off during the disinfection step. Other studies have reported increases in microbial numbers specifically bacterial counts following chlorine washing which was attributed to cross-contamination (Alvarado-Casillas et al. 2010; Gagliardi et al. 2003; Johnston et al. 2005).

Ethylene degreening resulted in a slight increase in bacterial counts on Clementines while the opposite trend was observed under non-ethylene conditions. In contrast, bacterial counts on Palmer navels increased regardless of the degreening conditions with more counts observed in the absence of ethylene and minimal shifts occurred in the presence of ethylene. Increases in bacterial counts under ethylene degreening conditions may be due to changes in $\mathrm{pH}$ levels of the fruit. Ethylene degreening was shown to reduce acidity levels in Mosambi oranges (Ladaniya and Singh 2001).

In the present study it was observed that degreening with or without ethylene increased fungal counts of Clementines, with a higher impact under non-ethylene conditions. On the contrary, degreening with or without ethylene decreased fungal populations on Palmer navels with a higher impact under ethylene conditions implying that ethylene checked the growth of fungi on Palmer navels. Degreening with or without ethylene reduced yeast counts on Clementines with higher reductions observed under ethylene conditions. Similarly, yeast populations on Palmer navels declined under ethylene degreening conditions but remained the same under non-ethylene degreening conditions. These results seem to suggest that the cool humid degreening conditions used in this study reduced yeast counts on fruit surfaces for 
both varieties but more so with ethylene application. Overall, our results suggest that ethylene degreening has varying impact on the microbial biome of the citrus carpoplane. The epiphytic microbiota on plant surfaces adapts differently to different environmental conditions due to fitness within the community context (Brandl 2006).

Although no change was observed in microbial populations of untreated Palmer navels held under ambient conditions for three days, it is still recommended to promptly wash and disinfect fruit after harvest as microbial populations can increase as was seen with Clementine fruit. De Roever (1998) pointed out that delaying transportation of freshly harvested produce to the packhouse can result in the proliferation of potentially present foodborne pathogens due to elevated temperatures.

\section{Pyrosequencing analysis}

Despite the recent advances in the use of pyrosequencing to study phytobiomes, we are not aware of such studies conducted to date to describe the impact of commercial postharvest treatments including degreening on community structure of citrus fruit surfaces. Our findings have confirmed the presence of taxa previously found to inhabit other crop species and others rarely encountered on the carpoplane. Diversity indices (Shannon and Chao1) were relatively high although the OTU rarefication plot failed to plateau at species or genus level, signifying lower bacterial richness. This suggests insufficient number of reads to capture all of the diversity within each sample, especially for the OTUs in low abundance. However, the number of sequences obtained per sample in this study is larger than that obtained in analysis using conventional cloning and sequencing methods, which are less than 200 in general.

\section{Microbial community variation during packhouse processing}

Freshly harvested samples showed the native microbial community on orange surfaces. Applying a fungicide drench to fruit prior to degreening resulted in the greatest reduction in species richness and abundance for fungi. However, species richness recovered with degreening. Drenching further removes some fruit surface microbes (Smilanick 2006). Given this removal of the natural microbiota may provide pathogenic microorganisms a more suitable niche for growth and establishment with reduced competition, especially if 
contamination occurs during processing steps (Narciso 2005). In the present study, drenching was carried out with fungicides (thiabendazole, 1000 ppm; pyremethanil, 1000 ppm; guazatine, $500 \mathrm{ppm}$ and 2.4-dichlorophenoxyacetic acid drenched) and this explains the massive decline in fungal diversity compared to bacterial diversity. Compared to fungal communities, bacterial communities had limited variation among the samples although the prevalence of unique OTUs was evident for the different samples suggesting that packhouse treatments may influence the growth of some bacteria over others. These results also indicate that bacterial communities were not greatly affected by the packhouse processes investigated in this study except that they influenced the relative abundance of the various taxa.

The highest microbial diversity was observed with untreated samples that were taken from the field and kept at room temperature for the duration of the degreening period (three days). The microbial community of these samples before storage had some genera including Diatrypaceae_unidentified, Dioszegia and Incertae_sedis_3_unidentified that were not detected after storage at room temperature. Compared to orchard environments, the packhouse has a more even temperature and humidity. This may explain the disappearance of some genera that were detected before storage as microbes more favourable to indoor environments were selected for.

Comparison of samples before drenching (freshly harvested) and drenched samples showed that while drenching decreased fungal communities, some communities were only detected after drenching. This suggests that drenching may select for a few genera although in general it eliminates most of the fungi. Although degreened samples had relatively higher diversity than drenched samples, drenched samples had eight genera that were not detected after degreening. Interestingly four dominant genera $(>10 \%)$ characterised degreened samples compared to one dominant genera detected in drenched samples.

Cluster analysis showed that similarity between populations was influenced by packhouse treatments. Cluster analysis revealed that bacterial communities on freshly harvested and degreened samples were more similar compared to drenched and untreated samples. In particular, drenched samples were in their own unique cluster while the other three samples were generally under one cluster. 
Our findings support the ecological thinking of a healthy climax community at point of harvest directly representing stability (Atlas and Bartha 1998). Any intervention treatment including washing and degreening will alter the natural ecological balance and prevent formation of a climax community. In the present study, both total counts and pyrosequencing analysis revealed that although drenching resulted in significant reductions in microbial populations, these populations were restored during ethylene degreening implying that the microbial shift was not permanent.

It is interesting to note that culture-dependent techniques showed no significant differences between microbial populations of freshly harvested and untreated Palmer navels. Conversely, pyrosequencing analysis showed a significant rise in microbial community diversity of Palmer navels due to storage under ambient room conditions for three days. A possible explanation to this observation may be the presence of viable-but-non-culturable (VBNCs) organisms under ethylene degreening which were not detected by culturedependent enumeration methods used in this study. Holding oranges outside the packhouse for long periods, a practice common in many packhouses during peak harvesting periods may lead to produce contamination and elevated microbial concentrations on orange surfaces as fruit are exposed to dust.

\section{Bacterial diversity on the citrus carpoplane}

The bacterial communities of the citrus carpoplane as represented by freshly harvested samples were dominated by the phyla Proteobacteria, Actinobacteria, Bacteroidetes and Deinoccoccus. These phyla have previously been reported as common inhabitants of aerial surfaces in other plant species such as grape leaves and berries (Leveau and Tech 2011), and tomato fruit and leaves (Ottesen et al. 2013; Telias et al. 2011). The carpoplane is populated by microbiota that is well adapted to the harsh environmental conditions such as low nutrient availability, desiccation, temperature fluctuation exposure to UV and agricultural pesticides (Lindow and Leveau, 2002). These groups probably form part of the core taxa of the navel orange carpoplane. However, we are not aware of any studies that have described the core bacterial microbiota of the orange carpoplane hence the need for more work to corroborate our findings. 
Of special interest is the predominance of Proteobacteria sequences on the orange carpoplane, considering that this phylum contains much of the human pathogens including pathogenic E. coli and Salmonella among other pathogenic species. The phylum Proteobacteria forms part of the natural microbiota of humans and animals (Lopez-Velasco et al., 2011) suggesting that their presence on orange surfaces may be partially due to external contamination sources. Given the current awareness in food safety it is important that packhouses adopt good agricultural practices and monitor for microbial contamination through the production system especially with reference to foodborne pathogens. It also remains to be investigated if the variation of fungal communities and their interactions with bacterial communities on the citrus carpoplane does not promote growth of bacteria in the phylum Proteobacteria.

At the genus level the groups Deinococcus, Sphingomonas, Methylobacterium, Dyadobacter, Belnapia, Kocuria, Pantoea and Enterococcus were detected on the orange carpoplane in varying relative abundances across samples. The genus Deinococcus was present in all samples accounting for $27 \%$ of the sequences of freshly harvested fruit but greatly reduced by drenching (5\%), enriched during ethylene degreening (10\%) and three-day storage under ambient indoor conditions (57\%). The high prevalence of the Deinococcus group on untreated and freshly harvested fruit implies that they form part of the native microbiota of oranges. This genus is also highly abundant on the phyllosphere of other plants (Redford et al. 2010) but was rarely found on Arabidopsis thaliana phyllosphere (Bodenhausen et al. 2013). Deinococcus are highly resistant to environmental hazards such as low nutrient supply, UV exposure, desiccation and other DNA damaging agents due an efficient DNA repair system (Lambais et al. 2006). Surprisingly, the fungicide drench and ethylene degreening used in our study greatly reduced the prevalence of this group on orange surfaces.

Another well represented genus was Sphingomonas. Yashiro et al. (2011) also found this genus in the apple phyllosphere. Sphingomonas was also the most abundantly represented genus on grape leaves (Leveau and Tech 2011). Members of this group are common colonisers of plant aerial surfaces and possess the ability to utilise a wide variety of substrates that are present in minute quantities on leaf surfaces (Delmotte et al. 2009). Despite their 
high prevalence on various plants of economic importance, the role of this genus on plant surfaces is not well known (Yashiro et al. 2011).

The genus Methylobacterium was also present in all samples with similar proportions in freshly harvested and degreened samples but elevated in drenched and untreated samples. Methylobacteria are ubiquitous plant colonisers deriving their name from the ability to utilise methanol as a survival mechanism on plant surfaces (Sy et al.2005) and were previously detected in high abundance on grape leaves (Leveau and Tech 2011).

The genus Belnapia is rarely found on plant surfaces but was detected in high abundances on degreened (33\%) and drenched (29\%) orange surfaces and in lower proportions on freshly harvested $(9 \%)$ and untreated $(12 \%)$ oranges. This genus appears to be part of the natural microbiota of oranges, whose growth was stimulated under ethylene degreening conditions. Belnapia are Gram-negative aerobic bacteria belonging to the family Acetobacteriaceae of the phylum Alphaproteobacteria (Chakravorty et al. 2015). This particular genus is not well studied hence its significance on plant surfaces and in human health are not known. The presence of the genus Belnapia on oranges in the present study may be ascribed to the ability of the Acetobacteria members to thrive in high sugar, low $\mathrm{pH}$ environments (Chakravorty et al. 2015) typical of citrus fruit. However, we did not come across any literature on the presence of this genus on plant surfaces. The association of Belnapia with oranges and other food crops has, to the best our knowledge, not been reported before and this is probably a novel finding that deserves further investigation.

Despite the wide distribution of the genus Pantoea on aerial surfaces of plants (Redford et al. 2010; Telias et al. 2011), this genus was present in small numbers in all samples and was not detected in drenched fruit samples. Yashiro et al. (2011) also reported very low prevalence of this genus on apple leaves with only one cloned sequence representing this group. In contrast the genus Pantoea dominated tomato fruit and leaf surfaces (Telias et al. 2011). In the present study, the genus Pantoea was eliminated by drenching but reverted to initial population prevalences under degreening conditions and increased by a magnitude of more than ten under ambient indoor conditions suggesting it to be a stable coloniser of the orange carpoplane. The genus Pantoea includes most of the recognised plant-associated coliforms 
(Leclerc et al. 2001) while some strains can also be opportunistic human pathogens (Cruz et al. 2007).

Enterococcus is a large and diverse group of lactic acid bacteria inhabiting the gastrointestinal tract of a wide variety of animals and has been isolated from fresh produce, soil, water and bird faeces (Chidamba and Korsten 2015). The genus was present in very low abundances in the present study. Other sequences that were detected in very small proportions on the orange biome included the taxa TM7, Planctomycetes and Verrucomicrobiota among others. These groups were also detected in low abundances on the spinach phyllosphere (Lopez-Velasco et al. 2011). Members of the Planctomycetes and the division TM7 are well adapted to survive under the harsh conditions including air-bone existence typical of the of plant surfaces (Yashiro et al. 2011). Verrucomicrobiota is not a well-studied group but is a common inhabitant of the rhizosphere (Da Rocha et al. 2009). The presence of rhizosphere bacteria on orange surfaces can be associated with rain splashes and wind events (Bodenhausen et al. 2013).

In this study all samples were characterised by the presence of a large number of unclassified bacterial sequences implying that the orange carpoplane is inhabited by novel sequences that have not yet been described or placed into recognised phylum within the RDP database (Anderson et al. 2008). Other studies have also reported similar results indicating the presence of rare lineages on the plant surface (Lopez-Velasco et al. 2011).

\section{Fungal diversity on the citrus carpoplane}

Fungal communities were dominated by the phyla Ascomycota and Basidiomycota and to a lesser extent Chytridimycota. Other studies have reported similar results on various plants including grape berries (Taylor et al. 2012) and olive fruits (Abdelfattah et al. 2015).Ten fungal genera dominated the orange surfaces including some important groups such as Davidiella, Cryptococcus, Penicillium, Epicoccum and Sporobolomyces.

The genus Davidiella was the most dominant at all processing stages with similar proportions observed in freshly harvested, drenched and untreated fruit but relatively less on degreened 
fruit. Davidiella belongs to the phylum Ascomycota and is commonly known by its anamorphic name, Cladosporium (Bensch et al. 2012). Davidiella dominates various plants including mango leaves (De Jager et al. 2001) citrus fruit, berries and grapes (Tournas and Katsoudas 2005; Taylor et al. 2014) and olive fruits (Abdelfattah et al. 2015). The dominance of this genus in our samples is not surprising given that they common indoor and outdoor fungi well adapted, non-pathogenic phyllosphere colonizers (Taylor et al. 2014).

The genus Sporobolomyces was present in all samples although it was dominant in degreened oranges suggesting that ethylene degreening conditions favoured growth of this group. Sporobolomyces are widely distributed yeasts commonly isolated from plant surfaces including apples, grapes, and raspberries (Janisiewicz 1994). Some members of this genus are used as biological control agents of postharvest pathogens (Janiswiecz 1994).

The genus Penicillium was also present in all samples with freshly harvested and degreened fruit having higher but similar prevalences compared to drenched and untreated samples which also had similar but lower proportions. Our findings suggest that the fungicide drench reduced the abundance of Penicillium but populations increased under degreening conditions. Research suggests that degreening at 20 to $22^{\circ} \mathrm{C}$ for periods of 3 to 5 days before fungicide applications is conducive to the development of green mould caused by Penicillium digitatum (Pers.:Fr) Sacc. (Smilanick et al. 2006). Species of Penicillium have been isolated from a variety of fruits and are major postharvest pathogens of citrus worldwide. Coprinellus was not detected on freshly harvested and untreated oranges but was present on drenched and degreened fruit suggesting contamination during fungicide drench or removal of competing organisms (Narciso 2005). Coprinellus is a widely distributed genus, commonly known as the copronoid mushrooms. The members include saprobes that are found growing in gardens, road sides, grassy debris, dung and decaying wood to name a few (Garcia et al., 1998). Its presence in this study is therefore surprising and may indicate contamination of the water used in the fungicide drench since it was not detected on unwashed oranges. Cryptococcus was present in all samples albeit in small proportions. Most members of this genus causes spoilage of fruit and vegetables (Aneja et al. 2014) while others have been used as biological control agents for postharvest fungal pathogens (Yu et al. 2007). 
As was observed with bacterial diversity, some fungal sequences remained unidentified implying that the ITS rDNA sequence information available in the public databases is still not comprehensive and that some fungal taxa are still to be described.

\section{Conclusion}

This work showed that postharvest treatments have significant influence on the population sizes of culturable bacteria, fungi and yeasts. Although culture-dependent techniques showed similar trends, the pyrosequencing approach provided a broader outlook of the effect of postharvest treatments on the on fungal and bacterial biomes of the citrus carpoplane. Pyrosequencing analysis demonstrated that the fungicide drench applied to early seasonal citrus fruit prior to degreening greatly reduces the fungal species richness and diversity. However, some fungal population groups may recover while others may even proliferating during ethylene degreening. The recovery of microbial densities during degreening after fungicide drench may offer an answer to the observed increased postharvest decay due to Penicillium spp. in degreened citrus. Additionally, our findings supported the concept that delays in packing citrus after harvest may result in microbial increase on fruit surfaces.

Our results confirmed the presence of taxa previously described on other crops including Penicillium spp. Bacterial genera known to contain potential human pathogens were also found to naturally inhabit the citrus carpoplane although no attempt was further made to identify the species identities of the sequences in these genera. Further studies should therefore be conducted to fill this information gap and to ascertain if human bacterial pathogens are part of the natural microbiome of the citrus carpoplane or are just ephemeral members. Future studies should also investigate the impact of these and other practices like cold chain management on the survival and persistence of foodborne pathogens and their interaction with native citrus carpoplane microbial communities on different varieties.

\section{References}

Abdelfattah, A., Wisniewski, M., Li Destri Nicosia, M.G., Cacciola, S.O. and Schena, L. (2016) Metagenomic analysis of fungal diversity on strawberry plants and the effect of 
management practices on the fungal community structure of aerial organs. PLoS ONE 11, e0160470.

Alvarado-Casillas, S., Ibarra-Sanchez, L.S., Martinez-Gonzales, N.E., Rodriguez-Garcia, M.O. and Castillo, A. (2010) Validation of a washing and sanitizing procedure for cantaloupes at a Mexican packing facility. J Food Prot 73, 362-365.

Andrews, J.H. and Harris, R.F. (2000) The ecology and biogeography of microorganisms of plant surfaces. Annu Rev Phytopathol 38, 145-180.

Aneja, K.R., Dhiman, R., Aggarwal, N.K., Kumar, V. and Kaur, M. (2014) Microbes associated with freshly prepared juices of citrus and carrots. Int $\mathrm{J}$ Food Sci doi.org/10.1155/2014/408085.

Atlas, R.M. and Bartha, R. (1998) Microbial ecology: fundamentals and applications. $4^{\text {th }}$ Edition. 177.

Brown, G.E. and Miller, W.R. (1999). Maintaining fruit health after harvest. Citrus Health Management 175-188.

Bensch, K., Braun, U., Groenewald, J.Z. and Crous, P.W. (2012) The genus Cladosporium. Studies in Mycology 72, 1-401.

Beuchat, L.R. and Ryu, J.H. (1997) Produce handling and processing practices. Emerg Infect Dis 3, 459-465.

Bodenhausen, N., Horton, M.W. and Bergelson, J. (2013) Bacterial communities associated with the leaves and the roots of Arabidopsis thaliana. PLoS ONE, 8, e56329.

Brandl, M.T. (2006) Fitness of human enteric pathogens on plants and implications for food safety. Annu Rev Phytopathol 44, 367-392.

Brown, G.E. (1986) Diplodia stem-end rot, a decay of citrus fruit increased by ethylene degreening treatment and its control. P Fl St Hortic Soc 99, 105-108.

Brown, G.E. (1992) Factors affecting the occurrence of anthracnose on Florida citrus. Proc Int Soc Citricult 3, 1044-1048.

Chakravorty, S., Sarkar, S. and Gachhui, R. (2015) Identification of new conserved and variable regions in the 16S rRNA gene of acetic acid bacteria and acetobacteraceae family. Mol Biol 49(5), 668-677. 
Chidamba, L. and Korsten, L. (2015) Pyrosequencing analysis of roof-harvested rainwater and river water used for domestic purposes in Luthengele village in the Eastern Cape Province of South Africa. Environ Monit Assess 187, 1-17.

Cole, J.R., Wang, Q., Fish, J.A., Chai, B., McGarrell, D.M., Sun, Y., Brown, C.T., PorrasAlfaro, A., Kuske, C.R. and Tiedje, J.M. (2013) Ribosomal Database Project: data and tools for high throughput rRNA analysis. Nucleic acids research, 42(Database issue): D633-D642; doi: 10.1093/nar/gkt1244 [PMID: 24288368].

Cruz, A.T., Cazacu, A.C. and Allen, C.H. (2007) Pantoea agglomerans, a plant pathogen causing human disease. J Clin Microbiol 45, 1989-1992.

Da Rocha, U.N., Van Overbeek, L. and Van Elsas, J.D. (2009) Exploration of hithertouncultured bacteria from the rhizosphere. FEMS Microbiol Ecol 69, 313-328.

De Jager, E. S., Wehner, F. C. and Korsten, L. (2001) Microbial ecology of the mango phylloplane. Microbial Ecol 42, 201-207.

De Roever, C. (1998) Microbial safety evaluations and recommendations on fresh produce. Food Cont 9, 321-347.

Delmotte, N., Knief, C., Chaffron, S., Innerebner, G., Roschitzki, B., Schlapbach, R. and Vorholt, J.A. (2009) Community proteogenomics reveals insights into the physiology of phyllosphere bacteria. P Natl Acad Sci 106, 16428-16433.

Eckert, J. and Eaks, I. (1989) Postharvest disorders and diseases of citrus fruits. In: The citrus industry ed. Reuther, W., Calavan, E., Carman, G. B. pp 179-260. University of California Press.

Edgar, R.C., Haas, B.J., Clemente, J.C, Quince, C. and Knight, R. (2011) UCHIME improves sensitivity and speed of chimera detection, Bioinformatics doi: 10.1093/bioinformatics/btr381 [PMID 21700674].

Gagliardi, J.V., Millner, P.D., Lester, G. and Ingram, D. (2003) On-farm and postharvest processing sources of bacterial contamination to melon rinds. J Food Prot 66, 82-87.

Garcia, M.A., Alonso, J., Fernandez, M.I. and Melgar, M.J. (1998) Lead content in edible wild mushrooms in northwest Spain as indicator of environmental contamination. Arch Environ Con Tox 34, 330-335. 
If you put this in you have to link it to the Salmonella statement and I don't (for now) want to link the two papers

Inceoglu, O., Al-Soud, W.A., Salles, J.F., Semenov, A.V. and van Elsas, J.D. (2011) Comparative analysis of bacterial communities in a potato field as determined by pyrosequencing. PLoS ONE 6, e23321.

Janisiewicz, W.J., Peterson, D.L. and Bors, R. (1994) Control of storage decay of apples with Sporobolomyces roseus. Plant Dis 78, 466-470.

Jensen, B., Knudsen, I.M., Andersen, B., Nielsen, K.F., Thrane, U., Jensen, D.F. and Larsen, J. (2013) Characterization of microbial communities and fungal metabolites on field grown strawberries from organic and conventional production. Int J Food Microbiol 160, 313-322.

Johnston, L.M., Jaykus, L.A., Moll, D., Martinez, M.C., Anciso, J., Mora, B. and Moe, C.L. (2005) A field study of the microbiological quality of fresh produce. J Food Prot 68, 1840-1847.

Keller, S.E., Chirtel, S.J., Merker, R.I., Taylor, K.T., Tan, H.L. and Miller, A.J. (2004) Influence of fruit variety, harvest technique, quality sorting, and storage on the native microflora of unpasteurized apple cider. J Food Prot 67, 2240-2247.

Ladaniya, M.S. and Singh, S. (2001) Use of ethylene gas for degreening of sweet (Citrus sinenesis Osbeck) cv. Mosambi orange. J Sci Ind Res 60, 662-667.

Lambais, M.R., Crowley, D.E., Cury, J.C., Bull, R.C. and Rodrigues, R.R. (2006) Bacterial diversity in tree canopies of the Atlantic forest. Science, 312, 1917-1917.

Leclerc, H.D.A.A., Mossel, D.A.A., Edberg, S.C. and Struijk, C.B. (2001) Advances in the bacteriology of the coliform group: their suitability as markers of microbial water safety. Ann Rev Microbiol 55, 201-234.

Leveau, J.H.J. and Tech, J.J. (2010) Grapevine microbiomics: bacterial diversity on grape leaves and berries revealed by high-throughput sequence analysis of 16S rRNA amplicons. In International Symposium on Biological Control of Postharvest Diseases: Challenges and Opportunities 905, 31- 42.

Lindow, S.E. and Leveau, J.H. (2002) Phyllosphere microbiology. Curr Opin Biotech 13, $238-243$. 
Lopez-Velasco, G., Welbaum, G.E., Boyer, R.R., Mane, S.P. and Ponder, M.A. (2011) Changes in spinach phylloepiphytic bacteria communities following minimal processing and refrigerated storage described using pyrosequencing of 16S rRNA amplicons. J Appl Microbiol 110, 1203-1214.

McHugh, T.A., Koch, G.W. and Schwartz, E. (2014) Minor changes in soil bacterial and fungal community composition occur in response to monsoon precipitation in a semiarid grassland. Microbial Ecol 68, 370-378.

Muyzer, G., de Waal, E.C. and Uitterlinden, A. (1993) Profiling of complex microbial populations using denaturing gradient gel electrophoresis analysis of polymerase chain reaction-amplified genes coding for 16S rRNA. Appl Environ Microbiol 59, 695-700.

Narciso, J.A. (2005) An assessment of methods to clean citrus fruit surfaces. P Fl St Hortic Soc 118, 437- 440 .

Nawrocki, E.P., Kolbe, D.L. and Eddy, S.R. (2009) Infernal 1.0: inference of RNA alignments. Bioinformatics 25, 1335-1337.

Ottesen, A.R., Pena, A.G., White, J.R., Pettengill, J.B., Li, C., Allard, S., Rideout, S., allarde, M., Hill, T., Evans, P., Strain, E., Musser, S., Knight, R. and Brown, E. (2013) Baseline survey of the anatomical microbial ecology of an important food plant: Solanum lycopersicum (tomato). BMC Microbiol 13, 114.

Peiffer, J.A., Spor, A., Koren, O., Jin, Z., Tringe, S.G., Dangl, J.L. and Ley, R.E. (2013) Diversity and heritability of the maize rhizosphere microbiome under field conditions. $P$ Natl Acad Sci 110, 6548 - 6553.

Perazzolli, M., Antonielli, L., Storari, M., Puopolo, G., Pancher, M., Giovannini, O., Pindo, M. and Pertota, I. (2014) Resilience of the natural phyllosphere microbiota of the grapevine to chemical and biological pesticides. Appl Environ Microbiol 80, 3585-3596.

Pinto, C., Pinho, D., Sousa, S., Pinheiro, M., Egas, C. and Gomes, A.C. (2014) Unravelling the diversity of grapevine microbiome. PLoS ONE 9, e85622.

Redford, A.J., Bowers, R.M., Knight, R., Linhart, Y. and Fierer, N. (2010) The ecology of the phyllosphere: geographic and phylogenetic variability in the distribution of bacteria on tree leaves. Environ Microbiol 12, 2885-2893. 
Ritenour, M.A., Miller, W.M. and Wardowski, W.W. (2003) Recommendations for degreening Florida fresh citrus fruits. Circular 1170. Horticultural Sciences Department, Florida Cooperative Extension Service, IFAS, University of Florida, Gainesville.

Smilanick, J.L., Mansour, M.F. and Sorenson, D. (2006) Pre-and postharvest treatments to control green mold of citrus fruit during ethylene degreening. Plant Dis, 90, 89-96.

Sy, A., Timmers, A.C., Knief, C. and Vorholt, J.A. (2005) Methylotrophic metabolism is advantageous for Methylobacterium extorquens during colonisation of Medicago truncatula under competitive conditions. Appl Environ Microbiol 71, 7245-7252.

Taylor, M.W., Tsai, P., Anfang, N., Ross, H.A. and Goddard, M.R. (2014) Pyrosequencing reveals regional differences in fruit-associated fungal communities. Environ Microbiol 16, 2848-2858.

Telias, A., White, J.R., Pahl, D.M., Ottesen, A.R. and Walsh, C.S. (2011) Bacterial community diversity and variation in spray water sources and the tomato fruit surface. BMC Microbiology 11, 81.

Tournas, V.H. and Katsoudas, E. (2005) Mould and yeast flora in fresh berries, grapes and citrus fruits. Int J Food Microbiol 105, 11-17.

Williams, T.R., Moyne, A.L., Harris, L.J. and Marco, M.L. (2013) Season, irrigation, leaf age, and Escherichia coli inoculation influence the bacterial diversity in the lettuce phyllosphere. PLOS ONE 8, e68642.

Weisberg, W., Barn, S., Pelletier, D. and Lane, D. (1991) 16S ribosomal DNA amplification for phylogenetic study. J Bacteriol 173, 697-703.

Yashiro, E., Spear, R.N. and McManus, P.S. (2011) Culture-dependent and cultureindependent assessment of bacteria in the apple phyllosphere. J Appl Microbiol 110, 12841296.

Zahavi, T., Droby, S., Cohen, L., Weiss, B. and Ben-Ari, R. (2015) Characterisation of the yeast flora on the surface of grape berries in Israel. VITIS J Grapevine Res 41, 203. 